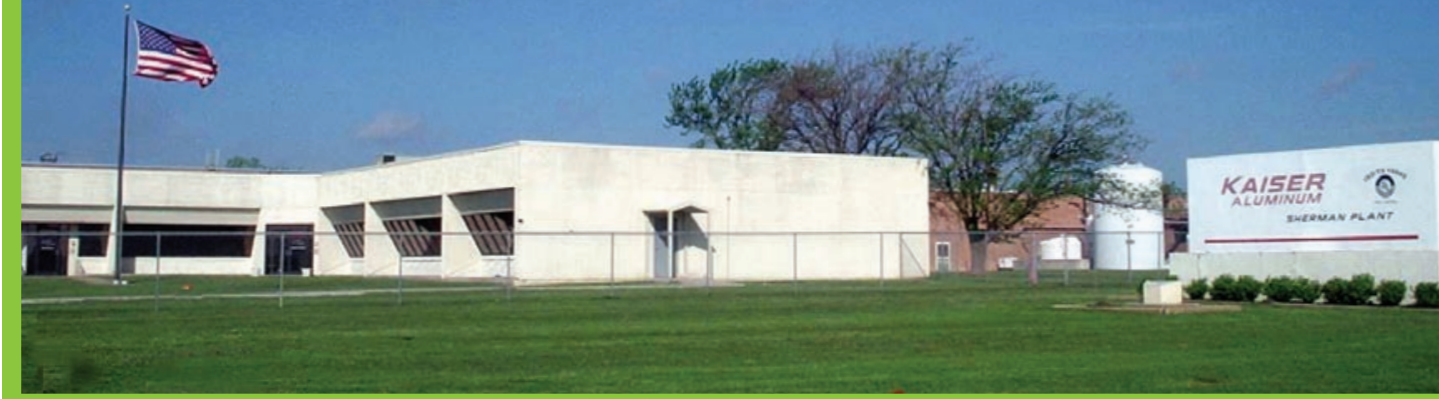

The Kaiser Aluminum plant in Sherman, Texas, improved its annual furnace energy intensity by $11.1 \%$ after implementing recommendations from the Save Energy Now assessment.

\title{
Energy Assessment Helps Kaiser Aluminum Save Energy and Improve Productivity DOE Software Adopted as Standard for Analyzing Plant Process Heating Systems Company-Wide
}

\section{Benefits}

Saved approximately

$\$ 360,000$ in annual

natural gas costs

Achieved annual energy

savings of nearly

45,000 MMBtu

Improved furnace energy

intensity by $\mathbf{1 1 . 1 \%}$ annually

Achieved a simple payback

of less than 1 month

Improved productivity

\section{Key Findings}

- Opportunities for energy efficiency do not require large capital expenditures to achieve significant energy savings.

- The DOE Process Heating Assessment and Survey Tool (PHAST) software was important to the success of the assessment at the Kaiser Aluminum plant in Sherman, Texas, and is now used to analyze process heating systems corporate-wide.

- Adjusting burner controls and repairing a furnace door sill and jamb resulted in significant energy savings.

- Energy efficiency measures can lead to improved production and other benefits such as reduced maintenance and lower emissions.

\section{Applications}

Process heating accounts for a large share of the energy used by the aluminum fabrication industry. Measures that improve furnace efficiency and reduce heat loss in the process heating applications of secondary aluminum plants can yield significant energy savings and better productivity.

\begin{abstract}
Summary
A U.S. Department of Energy-sponsored (DOE) Save Energy Now assessment was performed at Kaiser Aluminum's aluminum extrusion plant in Sherman, Texas, in 2006. Using DOE's Process Heating Assessment and Survey Tool (PHAST) software, DOE Energy Expert Richard Bennett of the Janus Technology Group worked with plant employees to analyze the plant's process heating systems. The assessment identified opportunities that would result in significant energy savings in some of the melting furnaces. By implementing these opportunities, plant personnel were able to achieve significant natural gas savings.
\end{abstract}

Employees at the Sherman plant wasted no time moving forward with the opportunities that had the greatest energy savings potential. First, they adjusted burner controls on one of the main reverberatory melting furnaces to lower excess oxygen levels. They also made some repairs to the furnace's door sill and jamb to prevent cold air from seeping into it. By implementing these measures the plant achieved annual energy savings of approximately 45,000 MMBtu and improved the furnace's energy intensity by $11.1 \%$ between 2006 and 2007. With project costs of approximately $\$ 28,000$ and energy cost savings of $\$ 360,000$, the simple payback was under 1 month. In addition, Kaiser Aluminum adopted the PHAST as the corporate tool for assessing process heating applications. To date, the company has used the tool to evaluate furnace efficiency at five other plants with casting operations. 


\section{Project Drivers}

At Kaiser Aluminum, energy efficiency is a high priority in keeping with the company's emphasis on Lean Manufacturing and Six Sigma methodologies. The Save Energy Now assessment revealed ways that would enable the plant to not only save energy, but also to improve production. The possibility of productivity improvements, coupled with significant energy savings, provided a high degree of motivation for the plant's employees to implement the most feasible recommendations from the assessment. Because these energy efficiency opportunities were cost-effective, the plant was able to execute them quickly and easily.

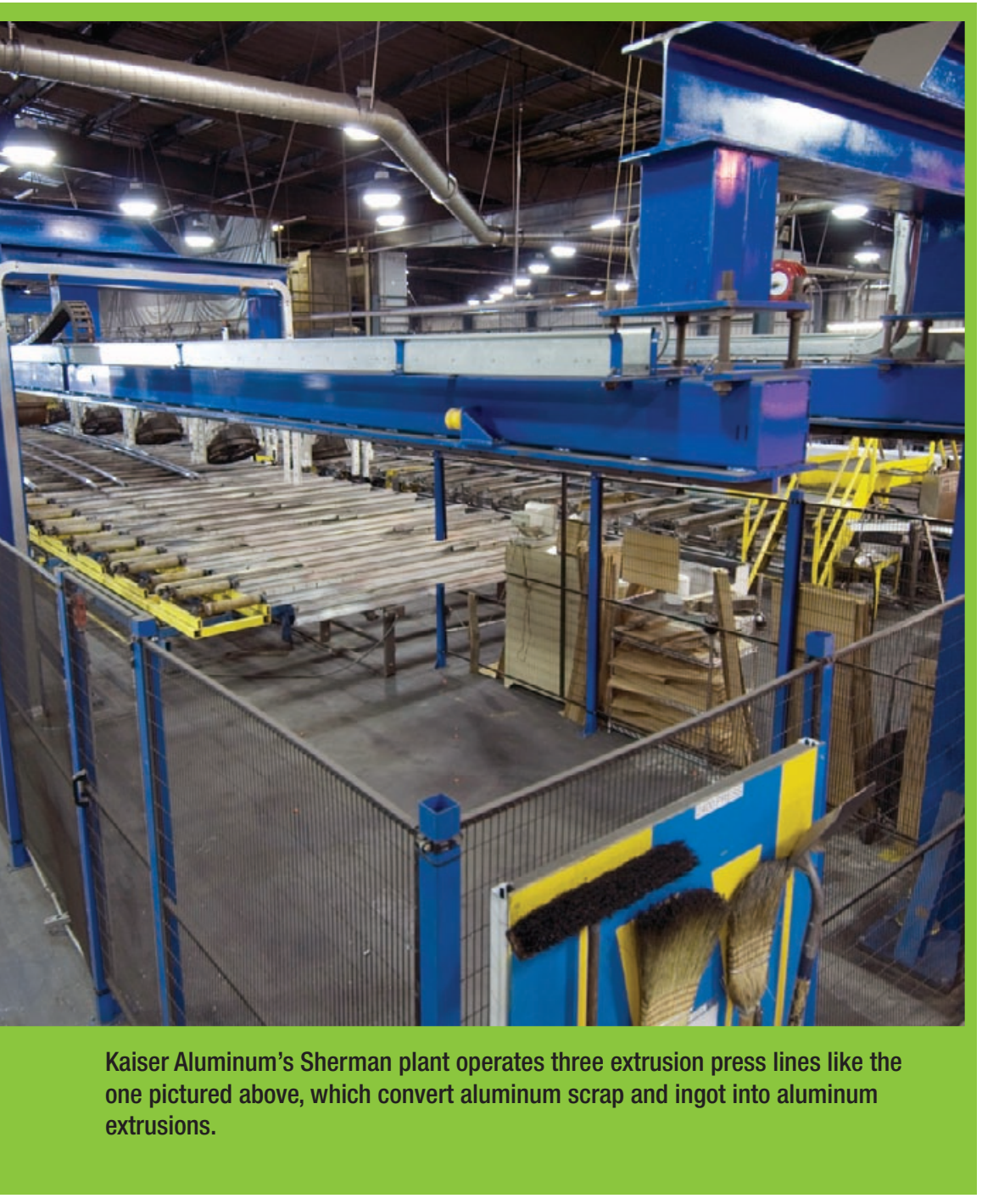

Company and Plant Background

Founded in 1946, Kaiser Aluminum is a leading producer of fabricated aluminum products for aerospace and high-strength, general engineering automotive and custom industrial applications. The company employs 2,000 people in 11 fabrication plants in North America and typically produces and ships more than 500 million pounds of aluminum products annually. In 2006, Kaiser's revenues were more than $\$ 1.3$ billion.

The Sherman, Texas, facility is a fully-integrated aluminum extrusion plant manufacturing quality fabricated aluminum products including sheet, plate, billets, redraw rods, extrusions, forgings, and tube products. The plant has two main operations: the cast house, where aluminum scrap and ingot are remelted and cast into direct chill billets; and the extrusion plant, where a portion of the cast house production is converted into aluminum extrusions.

The cast house has two natural gas-fired reverberatory melting furnaces that feed one gas-fired holding furnace, from which the billets are cast, and one homogenizing furnace where the billets are heated to produce a more uniform alloy structure. In the extrusion plant, three extrusion press lines are each served by a natural gas-fired tunnel-type billet heating furnace, along with three gas-fired aging ovens to heat-treat the finished extrusions. Natural gas consumption at the Sherman plant was more than 452,000 MMBtu in 2005.

\section{Assessment Overview}

The assessment at the Sherman plant was conducted by a DOE Energy Expert who is a qualified specialist on the use of PHAST, a software tool developed by DOE for analyzing process heating applications. The Energy Expert formed an assessment team with several plant employees to analyze the plant's furnaces using the PHAST. The team combined field test data with corporate energy use and production records on three representative furnaces to determine whether any improvements to equipment or operating conditions would improve energy efficiency. 


\section{Assessment Recommendations}

After analyzing the data using the PHAST software, the assessment team came up with three energy savings opportunities. They classified these projects based on expected energy savings, technical and economic feasibility, and payback periods of near- and mediumterm.

\section{Near-term opportunities}

- Burner Tuning - The assessment identified excess oxygen levels of $5 \%$ in the reverberatory furnace. This condition occurred during the furnace's high fire period, which lasted for slightly more than $50 \%$ of every melt cycle. By adjusting the air-to-gas ratio in the burner system from $5 \%$ to $2 \%$, the assessment showed the plant could lower the average energy use per hour in the high-fire period by approximately $16 \%$. This was estimated to yield natural gas savings of more than 18,000 MMBtu and approximately $\$ 218,000$ per year.

- Reduce Furnace Heat Losses- Upon close inspection of the same reverberatory furnace, the assessment team realized that there was some damage to the door and surrounding sill and jamb. This damage allowed cold air to leak into the furnace during the period of each melting cycle when the burners were off, causing the furnace to cool. During the next melting cycle, the burners needed to operate for a longer period of time to bring the furnace up to the required temperature. The assessment recommended repairing the door sill and jambs to improve the seal and keep cool air from infiltrating the furnace. It calculated the plant would save more than 19,000 MMBtu and achieve energy cost savings of more than $\$ 225,000$ annually from implementing this measure.

\section{Medium-term opportunity}

- Optimize Furnace Air Flow-Analysis of the homogenizing furnace found that it had poor air flow uniformity. Because of this condition, some sections of the furnace took longer to reach the necessary temperature. This increased the holding time and resulted in excess energy use and longer production cycles. The assessment projected correcting the air flow and temperature would yield annual energy savings of 1,621 MMBtu and \$19,000 per year. More significantly, the assessment also calculated this opportunity could reduce cycle time by up to $27 \%$, thereby increasing the number of loads that could pass through the furnace.

If implemented, the total annual energy cost savings from these measures was estimated at more than $\$ 462,000$

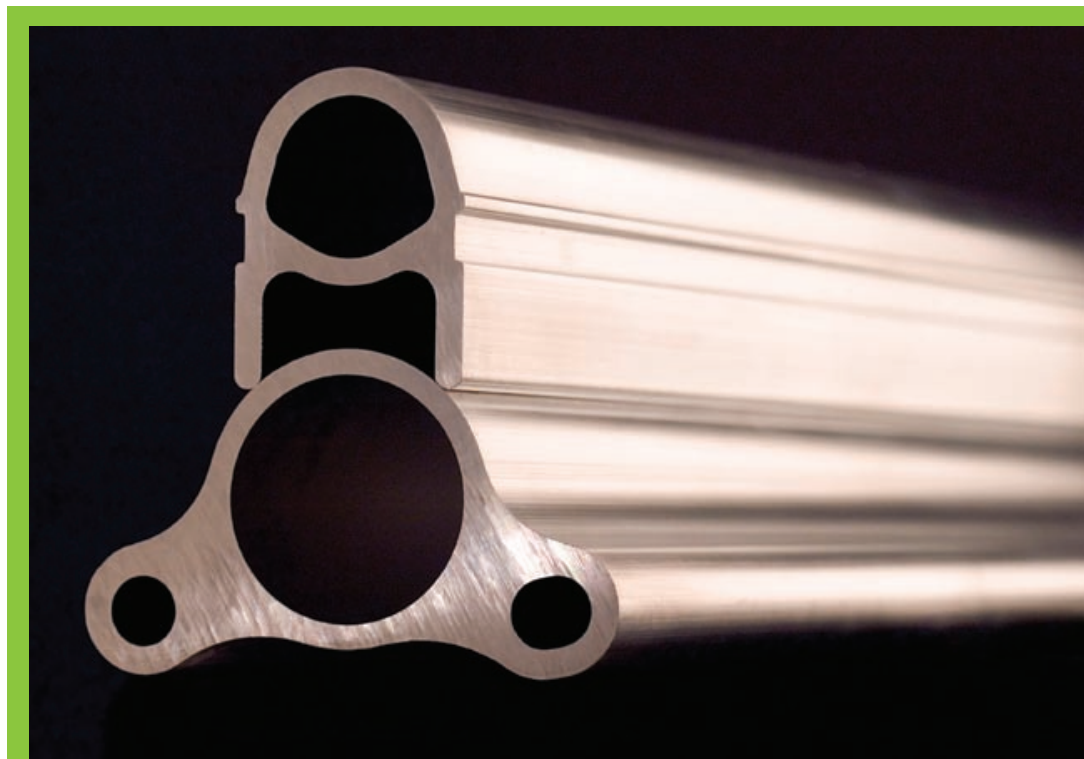

Kaiser Aluminum's Sherman plant makes custom parts for end-use applications in the transportation market, including trailer components and truck parts.

\section{"The Save Energy Now assessment was a tremendous asset in helping us identify energy savings opportunities. The process provided insight into new areas we had not previously consid- ered and validated merits of potential projects we previously identified. We found the experience quite helpful and have already begun to incorporate ideas from the assessment."}

\section{—David Conrow, Vice President, Kaiser Aluminum Production System}




\section{Results}

Eager to save energy, employees at the Sherman plant tuned the burner controls to adjust the excess oxygen levels in the reverberatory furnace. This brought the excess oxygen levels down to $2 \%$ and improved the furnace's thermal efficiency. Next, they fixed the furnace's door sill and jamb and improved the seal. They also used better As a result, the burners can bring the furnace to its required temperature in a shorter period of time. The company determined that correcting the airflow uniformity problems in the homogenizing furnace would require significant capital expenditures. Therefore, the project was not implemented, although it remains under serious consideration.

Despite changes to the product mix since the assessment that require additional heat treatment, the implemented measures:

- Yielded annual energy savings of approximately $45,000 \mathrm{MMBtu}$, representing nearly $33 \%$ of the furnace's and $10 \%$ of the plant's 2005 natural gas consumption, respectively

- Improved the furnace's energy intensity by $11.1 \%$

- Made the processes served by the reverberatory furnace less sensitive to volume fluctuations, which improved the consistency of the energy consumption per pound of product and reduced some production bottlenecks that were caused by volume fluctuations.

- Cost the company $\$ 28,000$ and resulted in energy cost savings of $\$ 360,000$, yielding a simple payback of less than 1 month.

\section{Kaiser Aluminum Utilizes DOE PHAST Software to Analyze Process Heating Systems Company-Wide}

The Sherman plant manufactures custom industrial electronic parts and water heater components.

- Based on the success of the assessment and the quality of the DOE training on process heating design criteria to prevent the seal from cracking.

- Five other Kaiser Aluminum plants with casting operations have used the PHAST to evaluate the efficiency of their respective process heating applications. As a result, significant opportunities have been identified and are going through the capital procurement process.

- The company uses the software tool as a reference instrument to normalize data between furnaces in different facilities.

With implementation costs of $\$ 28,000$ and cost savings of $\$ 360,000$, the simple payback was less than 1 month.

\section{Lessons Learned}

Often, industrial process heating applications can achieve significant energy savings by implementing measures that do not require large capital expenditures. At Kaiser Aluminum's plant in Sherman, Texas, misadjusted burner controls, some minor furnace door damage, and improper airflow characteristics reduced the efficiency of one of the plant's furnaces, which led to excess energy consumption and slower production. A Save Energy Now assessment performed using DOE's PHAST software was instrumental in bringing these issues to light and calculating the energy savings and production benefits that would result by taking corrective action. By implementing some of the assessment's central recommendations, the plant was able reduce energy usage and improve productivity.

In addition to the PHAST, other DOE software tools can similarly be used to analyze industrial systems and processes and generate significant energy savings opportunities. These include: AIRMaster+, the Fan System Assessment Tool (FSAT), MotorMaster+, the Steam System Assessment Tool (SSAT), the Pumping System Assessment Tool (PSAT), and 3E Plus ${ }^{\circledR}$. system analysis, Kaiser Aluminum adopted the assessment methodology and the PHAST software as their main diagnostic tool for process heating applications.

- The corporate energy manager visited each of the company's North American production facilities to introduce the tool and share the results from the Sherman plant.

\section{About Save Energy Now}

Through Save Energy Now, DOE's Industrial Technologies Program (ITP) helps industrial plants operate more efficiently and profitably by identifying ways to reduce energy use in key industrial process systems. Visit www.eere.energy.gov/industry/saveenergynow for more information.

\section{A Strong Energy Portfolio for a Strong America}

Energy efficiency and clean, renewable energy will mean a stronger economy, a cleaner environment, and greater energy independence for America. Working with a wide array of state, community, industry, and university partners, the U.S. Department of Energy's Office of Energy Efficiency and Renewable Energy invests in a diverse portfolio of energy technologies.

For more information, contact the EERE Information Center, 1-877-EERE-INF (1-877-337-3463), www.eere.energy.gov And visit the DOE Industrial Technologies Program home page: www. eere.energy.gov/industry 